\title{
Les dents incluses Traitement orthodontique et chirurgical
}

\section{Jean-Marie Korbendau, Antonio Patti}

Language: English

ISSN: 978-1-60831-746-2

Edition: 8/e

Publish Year: 2012

Pages: 520, illustrated

Price: $\$ 86.99$
The book "Les dents incluses. Traitement orthodontique et chirurgical" is fully reviewed and updated in terms of the surgical and orthodontic techniques. This book is divided into six chapters. Chapter one speaks about teeth eruption in mixt denture, orthodontic and radiographic assessment, and preventive treatment of impacted teeth. Maxillary incisors treatment is presented in chapter two. The chapter also tackles incisors eruption, supernumerary tooth elements and stages of orthodontic and surgical treatment of impacted teeth. Treatment of canine eruption anomalies are discussed in chapter three. It also provides information about eruption, caused root resorbtion, and orthodontic and surgical methods of treatment

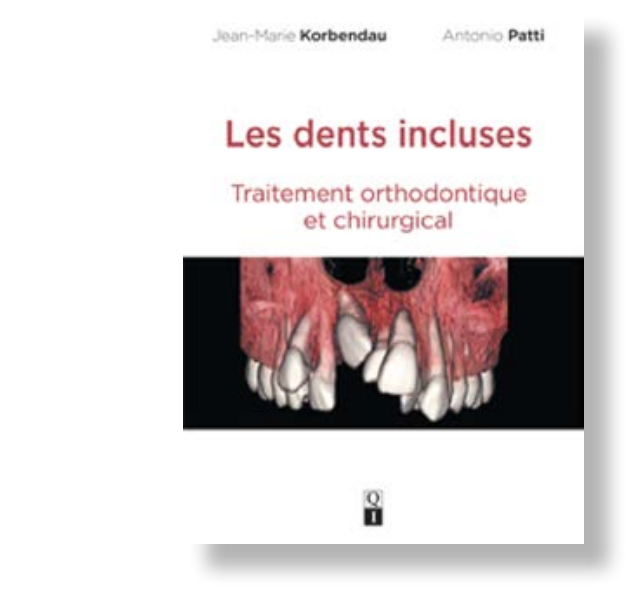

of various types of ectopies and transpositions. Problems of eruption and treatment plan of lower jaw incisors and canines are presented in chapter four. Eruption issues and treatment of premolars and molars are presented in the fifth chapter. The last chapter presents the supracrestal circumferential fibrotomy and relapses treatment.

Dr. Jean-Marie Korbendau and Dr. Antonio Patti manage to successfully complete an abundantly illustrated guide (950 figures) with clinical images as well as imaging of treatment stages chronology. 